\title{
Why apply agile? - A literature review on work outcomes in agile information systems development
}

\author{
Veronika Huck-Fries \\ Technical University of Munich \\ veronika.huck-fries@tum.de
}

\author{
Rosa Spitzer \\ Technical University of Munich \\ rosa.spitzer@tum.de
}

\begin{abstract}
Agile information systems development (ISD) has become a popular way to manage IT projects. One of the key claims of agile ISD is to increase employees' work outcomes, such as job satisfaction. However, the research landscape is heterogenous and lacks of a comprehensive overview. In this research, we set out to analyze and synthesize the current state of research on agile ISD and work outcomes by a systematic literature review. Overall, we found a trend of a positive relationship of agile ISD on work outcomes, although there is a variety of constructs that influence this relationship. We propose four directions for future research: perceptions of work, extended quantitative findings, multi-level effects and IT project success.
\end{abstract}

\section{Introduction}

In today's rapidly changing business and technology environments, software companies face the critical need of responding fast to volatile user requirements [1]. That equals unstable, complex project scopes which require lean and nimble processes to permit reactive planning and development [2]. At the same time, these companies are confronted with a scarcity of information systems (IS) specialists and a highly competitive labor market on the people side [3]. Work outcomes have been identified as a decisive factor in order to attract and retain information technology (IT) talents and thus reduce turnover costs [4] - one of the main and most costly challenges for organizations.

As an approach to tackle this challenge, companies increasingly adopted agile information systems development (ISD) [5]. Agile ISD provides the possibility to quickly react to varying customer demands and facilitate project planning, even if the target of a project cannot be exactly defined right from the beginning [6]. Instead of striving for the perfect, complete product right from the start, agile ISD prioritizes the customer's needs and gradually processes them in order to learn from feedback and drawbacks. Since studies have shown that failing in ISD projects can lead to a positive learning success, this approach promises beneficial long-term effects [7]. One of the striking aspects of agile ISD is to increase outcomes at work, such as motivation and job satisfaction [8-10]. The Agile Manifesto claims to value individuals and interaction over processes and tools. The principles state that motivated individuals who are provided with the required environment and support and are trusted to get the work done and show better performance. Due to these positive effects addressing prevailing challenges, agile practices have become an increasingly preferred alternative to traditional practices and are applied in companies of all sizes and industries [1, 11]. In 2020, 9 out of 10 software companies stated that they work according to agile principles [12].

However, empirical evidence on agile ISD and its effect on outcomes at work are diverging. Studies suggest a positive impact on programmers' satisfaction [13], while others found a decrease of job satisfaction among developers [14]. Existing research findings on the relationship between agile practices and work outcomes are scattered and miss a comprehensive overview. So far, there is little integration within the literature that provides a guideline how to conduct agile projects to affect work outcomes.

In this paper, we take a step towards the integration of the current state of research by reviewing and analyzing existing papers in the field of agile ISD and work outcomes. The review of the literature summarizes and classifies existing literature to provide a deeper understanding of the influence of agile practices on work outcomes. The following research question guides our literature review: How does agile ISD affect work outcomes?

The remainder of this work is structure as follow. Section 2 presents an overview of the literature on agile ISD. Section 3 describes the methodology, which is followed by the results and analysis of the findings in section 4. Section 5 provides a discussion of the findings including implications for theory and practice 
and directions for future research, ending up with a conclusion of the paper.

\section{Theory}

\subsection{Foundations of agile ISD}

[15] define agility as the ability to create change by also responding to change while creating a profitable business result. The three main characteristics of agility are incremental procedures, customer collaboration and the focus on people [16]. The Manifesto for Agile Software Development includes values and principles that describe best the characteristics of agile methods [17]. Their focus lies on individuals and interactions more than on processes and tools and they describe that the "highest priority is to satisfy the customer through early and continuous delivery of valuable software" $[17,18]$. Teams are characterized being cross-functional and selforganized [19-21]. Interactions with customers and other stakeholders take place at all times during the development process $[19,20,22]$ and enable the team to get feedback on their actual doing [18, 23].

The agile principles have completely moved the center of attention to people and change [11]. Because of the growing popularity agile practices have had in the field of ISD, they have attracted the attention not only of many researchers but also of many practitioners in other industries as well [24]. Project success factors in agile ISD can be classified into five categories: organizational, people, process, technical, and project. Yet, a motivated individual is one of the keystones of agile ISD [25]. The intention of features such as self-organization and continuous collaboration is to generate a more motivated team with a higher performance [26, 27].

\subsection{Current research on agile ISD}

With agile practices taking increasing ground, the scholars' interest in contributing research-based insights to an initially practitioner-dominated field grew. In their recent literature review, [28] reported only a handful of researchers devoted to the state of research in agile while the majority concentrated on agile methodology.

In 2002, [29] laid the foundation for the agile narrative by reviewing the still limited research on agile for the purpose of classifying and defining agile ISD approaches. Based on that, they analyzed and differentiated resultant methods. Two years later, [30] assayed empirical studies, anecdotal articles, and practitioners' learnings in a comprehensive review.
They discussed the roots of agile and criticism, added insights regarding the management's role and a guide to decide when to apply agile practices. Following, [31] examined 1,996 agile ISD studies of which they only identified 36 of an empirical nature. Within their investigation, they differentiated traditional from agile ISD, highlighted advantages as well as limitations and concluded with a call for both more and higher quality empirical research. Part of a special issue roughly a decade after the Agile Manifesto was created, [32] reflected upon the research progress. They overall found a steadily increasing number of publications and consequently highlighted several white spots to be considered in future research. These encompassed investigating experienced and large agile teams, setting managerial and especially organizational context, and reviewing agile ISD regarding its eligibility for open source and software as a service. Additionally, they ascertained the research focus shifting from methods such as pair programming and Extreme Programming (XP) towards flow based and lean ISD. They concluded with urging agile scholars to take a more theory-based approach to identify and embrace innovations earlier. Shortly thereafter, [33] published a review of 482 papers, again proving the lack of theoretical grounds (applied have solely been the complex adaptive systems-, control- and coordination theory) and need for more quantitative research (then only accounting for $34 \%$ ). Within another special issue, [34] enhanced the comprehension of agility, contributed to research rigor, and identified a need for more research going beyond the adoption to the stage of actual use of agile practices. They also highlighted the importance of studies concerned with agility and its interdependences in the organizational context. The most recent literature review is provided by [28], covering a total of 775 papers. Findings included different trends in agile ISD research: while topics allocated to the category "project, team, knowledge management, and leadership" are broadly covered, a research stream on social aspects was found to be clearly underdeveloped. In addition to that, they found the under-researched fields called by [32] still valid. This state of agile ISD research is enriched by some evidence on specific agile methods such as XP [2] and Scrum [e.g., 35, 36], different contexts like e.g., communication [37], global software engineering [38], user-centered ISD [39] and requirements engineering [40] or particular roles, such as project managers [41, 42].

Different agile practices can be used when running ISD projects. In this paper, we build on [43] who fundamentally differentiate between agile software development (ASD) practices (automated 
testing, automated builds, continuous integration, coding standards, refactoring, pair programming), and agile project management (APM) practices (daily stand up meeting, iterative delivery, retrospectives, burndown). The gap between ASD and APM research became further apparent: while literature reviews on ASD are scarce already, even less studies have been identified for APM. Most of them reviewed APM literature in a theoretical context such as project success [44], maturity models [45] or in comparison to traditional project management [46]. No study was found to provide a narrative review. Narrowing it further down, to date no scholar has applied the methodology of literature review in context with agile ISD and work outcomes. For work outcomes, we focus on job / work satisfaction and work engagement. Job satisfaction is defined as "the amount to which individuals perceive their job as sufficiently satisfactory to stay in it until they are either ready for other responsibilities" [47]. Work engagement is defined as " a positive, fulfilling, work-related state of mind that is characterized by vigor, dedication and absorption" [48].

\section{Research methodology}

Scopus, the largest scientific database for peerreviewed literature, served as first point of evaluation. Pre-defined queries and the advanced search mode are used to yield results. Following, a forward and backward search was carried out across further scientific resources. In line with [49], we first searched for contributions from top tier journals, increasing the probability to determine studies which have had a significant influence in either ASD, APM or work outcome literature. As recommended [49], the author decided to consider eight journals that happen to be in Senior Scholars' Basket of Journals [50]. In a second step, the search is broadened to less ranked journals and top management contributions. For the former, the researcher turns to the VHB ranking, the independent and leading journal assessment in German speaking countries, regularly published by the German Academic Association of Business Research [51]. They classify journals on a scale ranging from $\mathrm{A}+$ (excellent and internationally leading scientific business journal) to D (scientific business journals). For the latter, the list of 50 journals that the Financial Times (FT) uses to compile its Research Rank [52] will be consulted additionally. The top VHBorganizational (psychology) journals (ORG) complement the search. Acknowledging the broad scope of this work covering contributions from business-, IS- and organizational literature the researcher will further run an attempt without indicating the specific field of study. Subsequently, the researcher initiates a backward search and finally consults further scientific databases, aiming at the most accurate coverage possible. To propose relevant search queries and design the search process as efficient as possible, combinable search elements are determined as a start. Content-search elements encompass: "Agile Software Development", "Agile Project Management", "Information Systems Development" and "Work Outcomes". All contentsearch element-associations are then combined to different search queries. The search query is available from the authors upon request.

\section{Results}

Considering its emergence only three decades ago, the overall literature on agile has progressed well. Without literature constraints, the review yielded 8007 results on ASD or APM. Only 91 are within the top tier IS literature. Broadening the scope to IS ALL increased the number of publications significantly to 1156. Further widening the review to FT- and ORGliterature added only marginally more results. On the one hand, this is surprising as agile itself embraces and impacts various aspects of an organization, i.e., structural and psychological. On the other hand, it is consistent with previous findings such as APM and social aspects being still rarely covered topics. Limiting the search to work outcomes, two contexts have been considered. First, work outcomes in ISD generally which led to 768 publications when searching without literature focus, and 113 in IS ALL, from which 34 can be classified as results from top tier IS journals. Looking at work outcomes in the agile context, the number of publications is substantially lower: 72 in general, 14 in IS ALL, five within top tier journals. This result supports the need for further research in this field of study. Regarding FT- and ORG-literature, the same phenomenon could be observed for both these search foci: work outcomes in agile ISD has so far neither been a relevant topic in management nor organizational literature.

\subsection{Work outcomes in agile ISD}

Aiming at a holistic picture of the current research state on work outcomes in the agile context, we thoroughly reviewed the search results according to the suggestions of [53]. First, the resulting five publications from IS journals were taken into account, resulting in 14 articles. Second, the whole body of literature was considered, namely 72 publications. These 86 findings were then completed by a backward and forward search. To structure the review and its 
findings, [53] suggested a concept matrix, helping to synthesize and identify researched areas. Applying this approach, we created three matrices according to the previously described process: results for work outcomes in the agile context with (1) literature focus, (2) no literature constraints, and (3) backward and forward search. Within the matrices, results are compiled and clustered along the following criteria: the type of journal and its ranking, whether and which theoretical lens has been used, which method has been employed, and the publications' main findings. This approach further allowed to determine duplicates and irrelevant results.

Considering all matrices, 22 relevant publications resulted. While comparably few agile research applied theoretical foundations, the identified literature showed a good balance. While seven studies did not propose a theoretical model through which they conducted their analysis, three authors employed the Goal-Questions-Metrics Paradigm and another five the job characteristics model. The variety and roots of underlying theories indicate the broad scope of agile practices. With regard to the method, most scholars (twelve) used quantitative surveys, followed by three papers using interviews, two performing experiments, one conducting a literature review, and three with no specific approach. While [54] stated that in agile literature qualitative studies prevail, often drawing from a small sample size, it seems to be rather balanced regarding the topic of work outcomes. Content-wise, they can be divided into having explicitly researched work outcomes (eleven studies) or having implicitly found effects that impact work outcomes (ten studies). Findings if possible are subsequently split into either ASD or APM research.

\subsection{Agile software development}

Extant research on work outcomes in ASD is limited and mostly focuses on either a specific agile method or solely the individual-, team- or organizational dimension [55]. Despite these limitations, prior findings show a trend: an overall positive influence of agile practices on work outcomes. First indication therefore has been the fact that more general studies encompassing the two following reviews. First, [56] found a variety of studies reporting agile practices to enhance job satisfaction, productivity, and client contentment. Second, [57] systematically reviewed agile literature focusing on the public sector and declared it as promising transition for public organizations, fostering job satisfaction.

Looking at specific methods, pair programming has been proven to lead to higher satisfaction than developing alone [13, 58-60]. XP had the same effect but also increased productivity rates and improved the perception of the working environment [61]. The latter resonates with [62]. On the team level and analyzing scrum practices, [63] found an increase in collaboration, mutual support, appreciation, and defined objectives leading to higher motivation. When the method has not been stated explicitly, most research referred to pair programming, refactoring, and code standards at a minimum. Characteristics of agile practices such as increased collaboration, selforganizing teams, and collective code ownership correlated highest with work outcomes. The same was valid for time to market and the focus on technical quality - components that have been influenced by agile practices [64].

With regard to the individual level, [65] found agile developers more empowered which has proven to have a positive impact on work outcomes in literature. Reasons were broader access to information channels, more opportunities within the work task choice, and impact on development priorities compared to traditional developers. Although they stated agile developers have been satisfied, some challenges occurred such as neglecting communication practices when approaching deadlines. Additional indicators have been identified by [66]: being part of the decision-making process, access to interesting projects, interaction with users and direct user relationships stand exemplary for a rate of twice as many satisfied agile than traditional developers. They further found a positive correlation between job satisfaction and how advanced agile practitioners were. [67] provided a new perspective and inter alia examined personality factors, finding that developers who score high on agreeableness and conscientiousness, showed the highest satisfaction at work. They also stated a correlation between extraversion and software quality.

When reviewing the publications, the individual level has partially been reviewed by turning to job perceptions/characteristics. For instance, [67] found the satisfaction level dependent on task conflict and freedom of choice regarding the organization of their work. Employing the job characteristics model, [60] extended these findings and identified work sustainability (encompassing sustainable workload, low stress, high task significance), interdepartmental communication as well as among developers as factors increasing job satisfaction. [55] used the same theoretical lens but pioneered in explicitly distinguishing between ASD and APM practices. 
Table 1. Summary of findings

\begin{tabular}{|c|c|c|c|c|c|}
\hline \multirow{3}{*}{$\begin{array}{c}\text { Sou } \\
\text { rce }\end{array}$} & \multicolumn{5}{|r|}{ Agile ISD } \\
\hline & \multicolumn{2}{|c|}{ Work outcome } & \multicolumn{2}{|c|}{ Agile Practices } & \multirow[t]{2}{*}{ Findings } \\
\hline & $\mathrm{J} / \mathrm{WS}$ & WE & ASD & APM & \\
\hline [68] & $\mathrm{x}$ & & & & All factors of JCM contribute to JS in agile teams. \\
\hline [69] & $\mathrm{x}$ & & & & $\begin{array}{l}\text { Compared to non-agile, twice as many agile team members are } \\
\text { satisfied with their jobs / the maturity of use of agile practices is } \\
\text { decisive. }\end{array}$ \\
\hline [70] & $\mathrm{x}$ & & $\mathrm{x}$ & $\mathrm{x}$ & $\begin{array}{l}\text { Fatigue found as mechanism to explain job outcomes such as JS, } \\
\text { ASD reduced it, APM had no effect. }\end{array}$ \\
\hline [43] & $\mathrm{x}$ & & $\mathrm{x}$ & $\mathrm{x}$ & $\begin{array}{l}\text { Positive relationship between APM/ASD practices and job } \\
\text { characteristics, direct effects between ASD and JS/APM and job } \\
\text { autonomy }\end{array}$ \\
\hline [71] & $\mathrm{x}$ & & & & DevOps-teams are more satisfied with their jobs than agile teams. \\
\hline [72] & $\mathrm{x}$ & & $\mathrm{x}$ & & $\begin{array}{l}\text { Stand-up meetings reduce JS, trust, and well-being / } \\
\text { recommendations for change. }\end{array}$ \\
\hline [73] & $\mathrm{x}$ & & & & $\begin{array}{l}\text { Agile use: high professional efficacy, high JS, moderate work } \\
\text { overload, low cynicism / high agile use: higher JS, professional } \\
\text { efficacy, lower work ambiguity, work exhaustion, individual } \\
\text { autonomy / no difference regarding role conflict, work overload, } \\
\text { cynicism }\end{array}$ \\
\hline [56] & $\mathrm{x}$ & & & & $\begin{array}{l}\text { Agile development was found to enhance JS, project productivity, } \\
\text { customer satisfaction. }\end{array}$ \\
\hline [64] & $\mathrm{x}$ & & & & $\begin{array}{l}\text { Higher JS with agile, collaborative practices such as self-organizing } \\
\text { teams and collective code ownership correlated highest with JS, time } \\
\text { to market and focus on technical quality increases JS }\end{array}$ \\
\hline [60] & $\mathrm{x}$ & & & & $\begin{array}{l}\text { Factors increasing JS: work sustainability (sustainable workload, low } \\
\text { stress, high task significance), interdepartmental communication and } \\
\text { among developers, pair programming contributes to confidence and } \\
\text { thus both factors }\end{array}$ \\
\hline [74] & $\mathrm{x}$ & & & & $\begin{array}{l}\text { Teamwork quality has a strongly positive effect on learning and work } \\
\text { satisfaction but only marginally greater on team performance for } \\
\text { agile teams. }\end{array}$ \\
\hline [62] & $\mathrm{x}$ & & & & $\begin{array}{l}\text { Prevalence of agile methods lead to higher JS, overtime working has } \\
\text { no influence; working environment has been found to be positively } \\
\text { related to JS. }\end{array}$ \\
\hline [57] & $\mathrm{x}$ & & & & JS is greater when adopting agile methods in the public sector. \\
\hline [75] & $\mathrm{x}$ & & & & $\begin{array}{l}\text { JS mediates the effect of using ASD on the intention to stay (weaker } \\
\text { in large than in small firms). }\end{array}$ \\
\hline [76] & & & & $\mathrm{x}$ & $\begin{array}{l}\text { APM practices supported factors known to increase JS such as } \\
\text { recognition and rewards, job security and working environment. }\end{array}$ \\
\hline [67] & $\mathrm{x}$ & & & & $\begin{array}{l}\text { Highest JS when participants scored high on personality factors of } \\
\text { agreeableness and conscientiousness / high JS when participants } \\
\text { could decide how to organize their work / the greater the task } \\
\text { conflict, the lower the JS level / correlation between extraversion and } \\
\text { software product quality }\end{array}$ \\
\hline [77] & $\mathrm{x}$ & & $\mathrm{x}$ & $\mathrm{x}$ & $\begin{array}{l}\text { APM is positively related to JS, relationship of agile team JS is } \\
\text { negatively impacted by ASD. }\end{array}$ \\
\hline [78] & $\mathrm{x}$ & & & & $\begin{array}{l}\text { Proposed a model of self-leadership-culture which should generate } \\
\text { positive effects on JS, work engagement, performance, innovative } \\
\text { behavior. }\end{array}$ \\
\hline [79] & $\mathrm{x}$ & & & $\mathrm{x}$ & $\begin{array}{l}\text { XP practices enhanced JS, productivity, and led to a more } \\
\text { comfortably perceived work environment. }\end{array}$ \\
\hline [13] & $\mathrm{x}$ & & & $\mathrm{x}$ & $\begin{array}{l}\text { Pair programming leads to higher JS than independently working } \\
\text { programmers or nominal pairs. }\end{array}$ \\
\hline [80] & & $\mathrm{x}$ & & $\mathrm{x}$ & $\begin{array}{l}\text { Agile practices reduce job demands \& support job resources which } \\
\text { are positively related to work engagement. }\end{array}$ \\
\hline
\end{tabular}


They added findings including a positive relationship between both practices and how developers perceive job characteristics as well as direct effects between ASD practice use and job satisfaction. They conclude that both ASD and APM practices should be leveraged to maximize developer's satisfaction and call for further research, specifically with regard to job characteristics. [73] built on that and examined the extent of use of agile practices (considering pair programming, continuous integration, refactoring, regression testing, collective ownership, coding standards) with regard to several job perceptions. For the use of agile practices, they found high professional efficacy and job satisfaction, moderate work overload, and low cynicism. For high agile use, they stated an even higher professional efficacy and job satisfaction, lower work ambiguity, work exhaustion, and individual autonomy. Interestingly, they found no difference regarding role conflict, work overload, and cynicism. Considering the team level, [77] reported that the relationship of agile team satisfaction is negatively impacted by ASD. [81] explored teamwork quality and project success in agile teams. Thereby, they found agile having a strongly positive effect on learning and work satisfaction. At the same time, they reported only marginally greater team performance for agile teams. Concluding, [75] served a frequently addressed question and set agile practices into context with job satisfaction and retention. They confirmed their hypothesis that due to their positive effect on job satisfaction, ASD practices diminish the intention to quit. Interestingly, this relation was weaker in larger than in smaller organizations.

\subsection{Agile project management}

Based on APM literature and in regard to the context of work outcomes, [55] highlighted the following practices. (1) Daily stands-ups as daily, time-limited team meetings aiming at progress transparency and often guided by questions varying according to the agile method [82]. [72] found daily stand-up meetings to reduce job satisfaction, trust, and well-being but at the same time holding opportunities to empower teams when adjusted to the right direction. (2) Iterative delivery refers to gradual release and iteration planning shaped by direct feedback and leading to a better predictable velocity (defined as amount of work per cycle) once some iterations have been completed [55]. At the end of an iteration, (3) retrospectives take place, serving the purpose of reflection and uncovering of enhancement areas [82]. Employees linked scrum methods such as iteration planning and retrospectives as well as daily stand-up meetings with autonomy, feedback, and diverse skills, overall leading to more satisfied team members [68]. Throughout the project, (4) burndown charts provide visual support to keep track of finished and open assignments per iteration/ release, also contributing to better calculate velocity [83]. [55] stated a positive link between ASD, APM, and how individuals perceive job characteristics. They further indicated positive interaction effects between employing ASD and APM practices and its impact on job autonomy. [77] confirmed a positive relation between APM and work outcomes. With regard to the organizational level, [78] built on the aspect of agile self-organizing teams and proposed a model of self-leadership-culture which should generate positive effects on job satisfaction, work engagement, performance, and innovative behavior but needs further validation. Finally, [76] reported APM practices to support factors that are known to increase work outcomes such as recognition/rewards, job security, and the working environment.

\section{Discussion}

The use of agile practices and its effects on work outcomes constitute the main findings of this review. Within the following section, we discuss these in regard to future research directions.

\subsection{Perceptions of work}

Perceptions of work, such as work overload and role conflict, and their relationship on work outcomes constitute an often studies phenomenon in IS research. However, when it comes to the literature on agile ISD, we lack empirical evidence how and why perceptions of work affect outcomes. For example, [84] explored ASD practices (Scrum and Kanban) with regard to wellbeing and found most agile team members stating that they could not only ameliorate their performance but also their workload balance. [73] found slight role conflict for developers using agile practices and, contradictory to their expectations, no significant difference between low and high agile use clusters. Consequently, they suggested role conflict to constitute a rather resilient job perception and thus be liable to less variation. On the contrary, [85] found agile methods to reduce work exhaustion by significantly decreasing role conflict. The extant studies thus not only present inconsistent findings but also did not investigate potential effects on work outcomes which consequently calls for further exploration of perceptions such as work overload and role conflict in the agile ISD context. 


\subsection{Extending quantitative findings}

While the majority of existing studies used a quantitative research approach, IS researchers increasingly call for applying qualitative research approaches such as grounded theory [86] as well as mixed methods procedures [e.g., 87]. Particularly, researchers argue that agile ISD lacks of a "theoretical core" [88]; it might thus benefit from building theory.

When it comes to work outcomes in agile ISD projects, a mixed methods approach could help to explore how various roles of team members perceive their work and how this affects their results. For example, [42] found in a qualitative approach that project managers in agile ISD teams differ from other team members in terms of roles, responsibilities, group membership, tasks and activities. These differences might affect how work outcomes are shaped. As well, [89] found that professional self-efficacy was perceived as amplifier for agile practices and vice versa. Four dimensions contributing to professional self-efficacy were identified. (1) Effectiveness as developers agreed on higher effectivity compared to traditional ISD methods and reasoned with respecting industry best practices, more focus on customers and the actual software as well as improved interpersonal communication. (2) Efficiency due to streamlining documentation, rapid understanding of both big picture and all its elements due to regular stand-ups, and immediate process optimization thanks to retrospectives. (3) Quality primarily was led back to (automated) unit testing and its related small volume of code due to short iteration cycles which made room for structure enhancements. (4) Fitness with reality referred to agile being more compatible with nowadays project dynamics and customer requirements with practices allowing for fast adaptability responding to continuous change. This study might benefit from complementing the results with a quantitative study.

\subsection{Multi-level effects}

Although the majority of reviewed studies investigated work outcomes on a individual level, we argue that IS researchers currently leave promising insights out of sight when not taking the team and organizational level into account. In particular, a high level of work outcomes is supposed to be affected by characteristics of the team and organization. Hence, for future research, it is suggested to acknowledge the nature of nested data. Hierarchical structural equation modeling and random coefficient modeling are conceivable methods in this context, whereby the latter has been proven insightful in previous studies of agility [e.g., 85].

\subsection{ISD project success}

While the high rate of failure in ISD projects is a well-known challenge, our review of the literature evinced that none of these studies explored how work outcomes are related to ISD project success. It is commonly acknowledged that employees' job satisfaction positively affects organizational performance. Thus, researchers need to test whether work outcomes can act as a tool to manage ISD project success. In this case, practical implications for successfully running ISD projects can be made.

\subsection{Limitations}

Even though we aspired to review the whole body of literature as precisely as possible, several limitations must be acknowledged. First, the search process was solely conducted on Scopus, reasons included its standing as largest database of peerreviewed literature, coverage of all relevant research fields, and its advanced search mode allowing not only the export of references but also csv-files of search queries for analysis purposes. Despite these settings further databases might have yielded different results. Second, regarding the search process itself, two restrictions became apparent. First, the identification of top-tier journal publications by turning to VHB- and FT-rankings. Although both are highly recognized, others may have led to different results, considering a broader range of journals, especially in the organizational psychology research stream. Finally, the manual selection of keywords aggregated to search elements and then combined in search queries represent the most substantial limitation. Although, we performed an initial search focusing on extant narrative reviews to capture all relevant terms and used synonyms, it is undeniable that suitable literature might have been unintentionally excluded. Methods such as the backward and forward search were employed to mitigate that risk.

\subsection{Conclusion}

Work outcomes are fundamental predictors of organizational performance and project success. Despite a plethora of studies examining agile practices, work outcomes remain a scarcely regarded topic. In this r4esearch, we analyzed the current state of literature about the relationship of agile ISD and work outcomes. Ending up in 22 studies, our results 
indicate a tendency towards an overall positive relationship between agile ISD and outcomes at work. However, this relationship is sensitive for context, e.g. public sector [57], and applied methods, e.g. XP [79]. From our results, we derive four directions of future research: perceptions of work, extended quantitative findings, multi-level effects and IT project success.

\section{References}

[1] G. Lee and W. Xia. Toward Agile: An Integrated Analysis of Quantitative and Qualitative Field Data on Software Development Agility. MIS Quarterly, 34(1) (2010), p. 87-114. DOI: 10.2307/20721416.

[2] J. Erickson, K. Lyytinen, and K. Siau. Agile Modeling, Agile Software Development, and Extreme Programming: The State of Research. Journal of Database Management (JDM), 16(4) (2005), p. 88100. DOI: $10.4018 / \mathrm{jdm} .2005100105$.

[3] B. Prommegger, et al. Agile and Attached: The Impact of Agile Practices on Agile Team Members' Affective Organisational Commitment. (2019).

[4] D.H. McKnight, B. Phillips, and B.C. Hardgrave. Which reduces IT turnover intention the most: Workplace characteristics or job characteristics? Information \& Management, 46(3) (2009), p. 167-174. DOI: https://doi.org/10.1016/j.im.2009.01.002.

[5] D.K. Rigby, J. Sutherland, and A. Noble. Agile at Scale. Harvard Business Review, 96(3) (2018), p. 88-96.

[6] L. Williams, A Survey of Agile Development Methodologies. 2007.

[7] C. Pflügler, M. Wiesche, and H. Krcmar, 2016. The dualsided effect of project failure on IT professionals. in Proceedings of the 2016 ACM SIGMIS Conference on Computers and People Research. ACM, 33-37.

[8] M. Fowler and J. Highsmith. The agile manifesto. Software Development, 9(8) (2001), p. 28-32.

[9] V. Huck-Fries, F. Nothaft, and M. Wiesche, 2021. Investigating the Role of Stakeholders in Agile Information Systems Development Projects: A Mixed Methods Approach. in Proceedings of the 54th Hawaii International Conference on System Sciences. 6806.

[10] A. Memeti, et al., Motivation in IT Projects: Investigating the Effect of Agile Practices on Team Members' Intrinsic Motivation, in Pacific Asia Conference on Information Systems 2021: Virtual Conference.

[11] V. Lalsing, S. Kishnah, and S. Pudaruth. People factors in agile software development and project management. International Journal of Software Engineering \& Applications, 3(1) (2012), p. 117. DOI: 10.5121/ijsea.2012.3109.

[12] VersionOne. 14th annual state of agile report. 2020 23.08.2020 [cited 2020 July 23rd]; Available from: www.versionone.com.

[13] V. Balijepally, et al. Are two heads better than one for software development? The productivity paradox of pair programming. MIS Quarterly: Management Information Systems, 33(1) (2009), p. 91-118. DOI: $10.2307 / 20650280$.
[14] L. Fortmann, Agile or Fragile? The Depleting Effects of Agile Methodologies for Software Developers, in ECIS. 2018: Portsmouth.

[15] J.A. Highsmith and J. Highsmith. Agile software development ecosystems. 2002: Addison-Wesley Professional.

[16] K.S.a.J. Sutherland, The Scrum Guide ${ }^{\mathrm{TM}}$, Scrum, Editor. 2017.

[17] K. Beck, et al. Manifest for Agile Software Development. 2001 02.08.2019]; Available from: https://agilemanifesto.org.

[18] A. Cockburn and J. Highsmith. Agile software development: The people factor. Computer, 43(11) (2001), p. 131-133.

[19] S. Kudaravalli, S. Faraj, and S.L. Johnson. A Configural Approach to Coordinating Expertise in Software Development Teams. MIS Quarterly, 41(1) (2017), p. 43-64.

[20] T. Dingsøyr, et al. A decade of agile methodologies: Towards explaining agile software development. The Journal of Systems and Software, 85 (2012), p. 12131221.

[21] A. Cockburn. Agile software development: the cooperative game. 2 ed. 2007: Addison-Wesley.

[22] P. Serrador and J.K. Pinto. Does Agile work?-A quantitative analysis of agile project success. International Journal of Project Management, 33(5) (2015), p. 1040-1051.

[23] L. Williams and A. Cockburn. Agile software development: it's about feedback and change. IEEE Computer, 36(6) (2003), p. 39-43.

[24] R. Hoda, et al. Systematic literature reviews in agile software development: A tertiary study. Information and Software Technology, 85 (2017), p. 60-70.

[25] C.d.O. Melo, C. Santana, and F. Kon, 2012. Developers motivation in agile teams. in 2012 38th Euromicro Conference on Software Engineering and Advanced Applications. IEEE, 376-383.

[26] N.B. Moe, A. Aurum, and T. Dybå. Challenges of shared decision-making: A multiple case study of agile software development. Information and Software Technology, 54(8) (2012), p. 853-865.

[27] B. Ramesh, L. Cao, and R. Baskerville. Agile requirements engineering practices and challenges: an empirical study. Information Systems Journal, 20(5) (2010), p. 449-480.

[28] P. Diegmann, et al., Journey towards agility: Three decades of research on agile information systems development, in International Conference on Information Systems. 2018: San Francisco.

[29] P. Abrahamsson, et al. Agile software development methods: Review and analysis. VTT Technical Report, (2002), p. 107.

[30] D. Cohen, M. Lindvall, and P. Costa. An introduction to agile methods. Advances in Computers, 62(03) (2004), p. 1-66.

[31] T. Dybå and T. Dingsøyr. Empirical studies of agile software development: A systematic review. Information and Software Technology, 50(9-10) (2008), p. 833-859. DOI: http://dx.doi.org/10.1016/j.infsof.2008.01.006. 
[32] T. Dingsøyr, et al. A decade of agile methodologies: Towards explaining agile software development. Journal of Systems and Software, 85(6) (2012), p. 1213-1221. DOI: 10.1016/j.jss.2012.02.033.

[33] M. Hummel, 2014. State-of-the-art: A systematic literature review on agile information systems development. in 2014 47th Hawaii International Conference on System Sciences. IEEE, 4712-4721.

[34] P. Abrahamsson, K. Conboy, and X. Wang. 'Lots done, more to do': the current state of agile systems development research. European Journal of Information Systems, 18(4) (2017), p. 281-284. DOI: https://doi.org/10.1057/ejis.2009.27.

[35] B.V. De Carvalho and C.H.P. Mello. Scrum agile product development method-literature review, analysis and classification. Product: Management and Development, 9(1) (2011), p. 39-49. DOI: 10.4322/pmd.2011.005.

[36] E. Hossain, M.A. Babar, and H.-y. Paik, 2009. Using scrum in global software development: a systematic literature review. in 2009 Fourth IEEE International Conference on Global Software Engineering. Ieee, 175184.

[37] M. Hummel, C. Rosenkranz, and R. Holten. The Role of Communication in Agile Systems Development. Business \& Information Systems Engineering, 5(5) (2013), p. 343-355. DOI: 10.1007/s12599-013-0282-4.

[38] S. Jalali and C. Wohlin. Global software engineering and agile practices: a systematic review. Journal of Software: Evolution and Process, 24(6) (2012), p. 643659. DOI: $10.1002 / \mathrm{smr} .561$.

[39] M. Brhel, et al. Exploring principles of user-centered agile software development: A literature review. Information and Software Technology, 61 (2015), p. 163-181. DOI: 10.1016/j.infsof.2015.01.004.

[40] I. Inayat, et al. A systematic literature review on agile requirements engineering practices and challenges. Computers in Human Behavior, 51 (2015), p. 915-929. DOI: $10.1016 /$ j.chb.2014.10.046.

[41] V. Huck-Fries, et al., 2020. The ambiguous role of managers in agile information systems development projects; Part of the symposium "Advancing the Understanding of Agility and Agile Methods in Organizations". in 80th Annual Meeting of the Academy of Management.

[42] L. Mueller and J. Toutaoui. Who Am I and What Am I Doing Here?-IT Project Manager Identity in Agile ISD Team Settings. (2020).

[43] J. Tripp, C. Riemenschneider, and J. Thatcher. Job Satisfaction in Agile Development Teams: Agile Development as Work Redesign. Journal of the Association for Information Systems, 17(4) (2016), p. 267. DOI: $10.17705 / 1$ jais.00426.

[44] T. Bergmann and W. Karwowski, 2018. Agile project management and project success: A literature review. in International Conference on Applied Human Factors and Ergonomics. Springer, 405-414.

[45] L.F. Chagas, et al., 2014. Systematic Literature Review on the Characteristics of Agile Project Management in the Context of Maturity Models. in International Conference on Software Process Improvement and
Capability Determination. Cham: Springer International Publishing, 177-189.

[46] M. Špundak. Mixed agile/traditional project management methodology-reality or illusion? Procedia-Social and Behavioral Sciences, 119 (2014), p. 939-948. DOI: 10.1016/j.sbspro.2014.03.105

[47] R. Hoppcock. Job Satisfaction. 1935, New York: Harper and Brothers.

[48] W.B. Schaufeli and A.B. Bakker. Defining and measuring work engagement: Bringing clarity to the concept. Work engagement: A handbook of essential theory and research, 12 (2010), p. 10-24.

[49] J. Webster and R. Watson, Analyzing the Past to Prepare for the Future: Writing a Literature Review, in MIS Quarterly: Management Information Systems. 2002, MIS Quarterly. p. 13-23.

[50] AIS. Senior IS Scholars' Basket of Journals. Association for Information Systems - 12th Americas Conference On Information Systems, AMCIS 2006, (2014).

[51] VHB. Liste der Fachzeitschriften in VHBJOURQUAL3. 2020 [cited 2020 September 15]; Available from: https://vhbonline.org/vhb4you/vhbjourqual/vhb-jourqual-3/gesamtliste.

[52] L. Ormans. 50 Journals used in FT Research Rank. 2016 [cited 2020 September 15]; Available from: https://www.ft.com/content/3405a512-5cbb-11e18f1f-00144feabdc0.

[53] J. Webster and R.T. Watson. Analyzing the past to prepare for the future: Writing a literature review. MIS Quarterly, (2002), p. xiii-xxiii. DOI: 10.2307/4132319.

[54] P. Serrador and J. Pinto. Does Agile Work?-A Quantitative Analysis of Agile Project Success. International Journal of Project Management, 33(5) (2015), p. 1040-1051. DOI: 10.1016/j.ijproman.2015.01.006.

[55] J. Tripp, C. Riemenschneider, and J. Thatcher. Job Satisfaction in Agile Development Teams: Agile Development as Work Redesign. Journal of the Association for Information Systems, 17(4) (2016), p. 267-307. DOI: 10.17705/1jais.00426.

[56] T. Dyba and T. Dingsoyr. What do we know about agile software development? IEEE Software, 26(5) (2009), p. 6-9. DOI: 10.1109/MS.2009.145.

[57] I. Vacari and R. Prikladnicki, 2015. Adopting agile methods in the public sector: A systematic literature review. in Proceedings of the International Conference on Software Engineering and Knowledge Engineering, SEKE. 709-714.

[58] L. Williams, et al. Strengthening the case for pair programming. IEEE software, 17(4) (2000), p. 19-25.

[59] J.T. Nosek. The case for collaborative programming. Commun. ACM, 41(3) (1998), p. 105-108. DOI: 10.1145/272287.272333.

[60] W. Pedrycz, B. Russo, and G. Succi. A model of job satisfaction for collaborative development processes. Journal of Systems and Software, 84(5) (2011), p. 739752. DOI: $10.1016 /$ j.jss.2010.12.018.

[61] K. Mannaro, M. Melis, and M. Marchesi, 2004. Empirical analysis on the satisfaction of IT employees comparing XP practices with other software 
development methodologies. in International Conference on Extreme Programming and Agile Processes in Software Engineering. Springer, 166-174.

[62] A. Tarasov, 2019. Impact of lifestyle and working process organization on the job satisfaction level of software engineers. in Proceedings - 2019 IEEE/ACM 41st International Conference on Software Engineering: Companion, ICSE-Companion 2019. 177-179.

[63] O. McHugh, K. Conboy, and M. Lang. Using agile practices to influence motivation within it project teams. Scandinavian Journal of Information Systems, 23(11) (2011), p. 85-110.

[64] M. Kropp, et al., 2018. Satisfaction, Practices, and Influences in Agile Software Development. in ACM International Conference Proceeding Series.

[65] B. Tessem. Individual empowerment of agile and nonagile software developers in small teams. Information and Software Technology, 56(8) (2014), p. 873-889. DOI: 10.1016/j.infsof.2014.02.005.

[66] G. Melnik and F. Maurer, 2006. Comparative analysis of job satisfaction in agile and non-agile software development teams. in International Conference on Extreme Programming and Agile Processes in Software Engineering. Springer, 32-42.

[67] S. Acuña, M. Gómez, and N. Juristo. How do personality, team processes and task characteristics relate to job satisfaction and software quality? Information and Software Technology, 51(3) (2009), p. 627-639. DOI: 10.1016/j.infsof.2008.08.006.

[68] B. Tessem and F. Maurer, 2007. Job Satisfaction and Motivation in a Large Agile Team. in International Conference on Extreme Programming and Agile Processes in Software Engineering. Springer, 54-61.

[69] G. Melnik and F. Maurer. Comparative analysis of job satisfaction in agile and non-agile software development teams. Extreme Programming and Agile Processes in Software Engineering, (2006), p. 32-42.

[70] L. Fortmann-MÃ/4ller. Energizing or Depleting? Understanding the Effects of Agile Methodologies on Individual Software Developers ${ }^{\mathrm{TM}}$ Resources. (2018).

[71] A. Hemon, L. Monnier-Senicourt, and F. Rowe, 2018. Job Satisfaction Factors and Risks Perception: An embedded case study of DevOps and Agile Teams. in ICIS. San Francisco.

[72] V. Stray, N.B. Moe, and D.I. Sjoberg. Daily Stand-Up Meetings: Start Breaking the Rules. IEEE Software, (2018).

[73] W. Sun and C. Schmidt. Practitioners' AgileMethodology Use and Job Perceptions. IEEE Software, 35(2) (2018), p. 52-61. DOI: 10.1109/MS.2018.1661333.

[74] Y. Lindsjørn, et al. Teamwork quality and project success in software development: A survey of agile development teams. Journal of Systems \& Software, 122 (2016), p. 274-286. DOI: 10.1016/j.jss.2016.09.028.

[75] T.K. Setor and D. Joseph. When Agile Means Staying: A Moderated Mediated Model. Journal of Computer Information Systems, (2020), p. 1-10. DOI: $10.1080 / 08874417.2020 .1759160$.
[76] L. Issa, et al., 2019. Employee Retention in Agile Project Management. in 2019 10th International Conference on Information and Communication Systems, ICICS 2019. 160-165.

[77] S. Gupta, et al. Impact of IS agility and HR systems on job satisfaction: an organizational information processing theory perspective. Journal of Knowledge Management, 23(9) (2018), p. 1782-1805. DOI: 10.1108/JKM-07-2018-0466.

[78] E.M. Bracht, N.M. Junker, and R. van Dick. Exploring the social context of self-leadership-Self-leadershipculture. Journal of Theoretical Social Psychology, 2(4) (2018), p. 119-130. DOI: 10.1002/jts5.33.

[79] K. Mannaro, M. Melis, and M. Marchesi. Empirical analysis on the satisfaction of IT employees comparing XP practices with other software development methodologies. Extreme Programming and Agile Processes in Software Engineering, (2004), p. 166-174. DOI: $10.1007 / 978-3-540-24853-8 \_19$.

[80] V. Huck-Fries, et al., 2019. The Role of Work Engagement in Agile Software Development: Investigating Job Demands and Job Resources. in 52nd Hawaii International Conference on System Sciences. Hawaii, 7048-7056.

[81] Y. Lindsjørn, et al. Teamwork quality and project success in software development: A survey of agile development teams. Journal of Systems and Software, 122 (2016), p. 274-286. DOI: 10.1016/j.jss.2016.09.028.

[82] K. Schwaber and M. Beedle. Agile software development with Scrum. Vol. 1. 2002: Prentice Hall Upper Saddle River.

[83] J. Sutherland. Inventing and Reinventing SCRUM in five Companies. Cutter IT Journal, 14 (2001), p. 5-11.

[84] M. Laanti, 2013. Agile and Wellbeing--Stress, Empowerment, and Performance in Scrum and Kanban Teams. in 2013 46th Hawaii International Conference on System Sciences. IEEE, 4761-4770.

[85] V. Venkatesh, et al. How agile software development methods reduce work exhaustion: Insights on role perceptions and organizational skills. Information Systems Journal, 30(4) (2020), p. 733-761. DOI: 10.1111/isj.12282.

[86] M. Wiesche, et al. Grounded Theory Methodology in Information Systems Research. MIS Quarterly: Management Information Systems, 41(3) (2017), p. 685-701. DOI: 10.25300/MISQ/2017/41.3.02.

[87] V. Venkatesh, S.A. Brown, and Y.W. Sullivan. Guidelines for conducting mixed-methods research: An extension and illustration. Journal of the Association for Information Systems, 17(7) (2016), p. 2.

[88] J. Tripp, J. Saltz, and D. Turk, 2018. Thoughts on Current and Future Research on Agile and Lean: Ensuring Relevance and Rigor. in Hawaii International Conference on System Sciences. Hawaii.

[89] D. Bishop, A.V. Deokar, and S. Sarnikar. On Understanding Preference for Agile Methods Among Software Developers. Information Resources Management Journal, 29(3) (2016), p. 12-36. DOI: 10.4018/IRMJ.2016070102. 